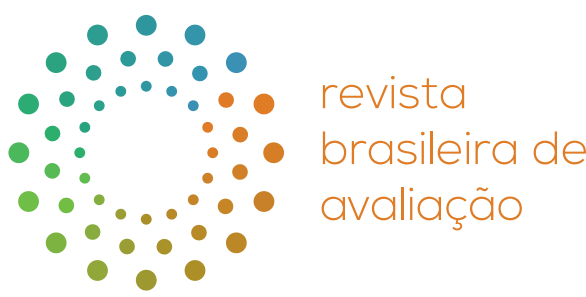

\title{
Lente Preta - avaliação e equidade racial: Manifesto por uma avaliação antirracista
}

\author{
Black Lens - evaluation and racial equity: Manifest for an anti-racist \\ evaluation
}

Diana Mendes dos Santos ${ }^{1}$ (negra) (ㄷ, Kleber Valadares ${ }^{2 *}$ (negro) (), Marcia Malaquias Braz ${ }^{3,4}$ (negra) (1), Nilson Vieira Oliveira ${ }^{5}$ (negro) (1), Walquiria Tiburcio² (negra) (1)

${ }^{1}$ Instituto Ibirapitanga, Rio de Janeiro, RJ, Brasil

${ }^{2}$ Move Social, São Paulo, SP, Brasil

${ }^{3}$ Faculdade Cesgranrio, Rio de Janeiro, RJ, Brasil

${ }^{4}$ Universidade Federal do Rio de Janeiro (UFRJ), Rio de Janeiro, RJ, Brasil

IInstituto Lima Barreto, São Paulo, SP, Brasil

COMO CITAR: Santos, Diana Mendes dos, Valadares, Kleber, Braz, Marcia Malaquias, Oliveira, Nilson Vieira, \& Tiburcio, Walquiria (2022). Lente preta - avaliação e equidade racial: Manifesto por uma avaliação antirracista. Revista Brasileira de Avaliação, 11(1), e110222. https://doi.org/10.4322/rbaval202211002

\section{Resumo}

Os processos de avaliação, em sua maioria, ainda têm sido demandados e conduzidos de forma a não se considerar o racismo estrutural em muitos casos. A questão racial acaba sendo, constantemente, uma categoria de análise secundarizada ou ignorada nos processos avaliativos. Nesse sentido, o presente manifesto enfatiza a importância de que projetos, programas e políticas sejam avaliados em busca de equidade racial. As reflexões são fruto da atuação de um movimento de avaliadoras/es negras/os que compreendem que a sua negritude fortalece e impulsiona leituras de mundo sob as lentes de quem não só vê a questão racial, mas também as vive, dentro e fora do campo da avaliação.

Palavras-chave: Avaliação. Equidade racial. Racismo estrutural. Antirracismo.

\section{Abstract}

Evaluation processes, in their majority, have still been demanded and conducted in a way that structural racism is not considered in many cases. The racial issue is constantly a secondary or ignored category of analysis in the evaluation processes. In this sense, this article emphasizes the importance of evaluating projects, programs, and policies in search of racial equity. The reflections are the result of the work of a movement of black evaluators who understand that their blackness strengthens and promotes readings of the world under the lenses of those who not only see the racial issue, but also live it, inside and outside the field of evaluation.

Keywords: Evaluation. Racial equity. Structural racism. Antiracism.
A RBAVAL apoia os esforços relativos à visibilidade dos autores negros na produção científica. Assim, nossas publicações solicitam a autodeclaração de cor/etnia dos autores dos textos para tornar visível tal informação nos artigos.

Recebido: Dezembro 20, 2021

Aceito: Janeiro 20, 2022

*Autor correspondente:

Kleber Valadares

E-mail: kleber@move.social

\section{(cc) BY}

Este é um artigo publicado em acesso aberto (Open Access) sob a licença Creative Commons Attribution, que permite uso, distribuição e reprodução em qualquer meio, sem restrições desde que o trabalho original seja corretamente citado. 
No Brasil, institutos, fundações, empresas e poder público têm se apoiado cada vez mais em processos de avaliação para aperfeiçoar políticas, programas e projetos e dar mais transparência e maior legitimidade às suas ações.

A adoção sistemática de instrumentais técnicos e o uso de parâmetros para analisar o alcance e a efetividade das ações realizadas têm permitido um olhar mais qualificado para tais ações. Isso evidencia o quão significativos são os ganhos na condução de processos avaliativos, e talvez, por isso, o uso da avaliação esteja sendo cada vez mais difundido e incorporado aos processos de gestão por diferentes instituições.

Apesar da difusão da prática avaliativa, é perceptível que os processos de avaliação ainda têm sido demandados e conduzidos por profissionais e instituições cujo perfil, leitura de mundo e horizonte de preocupações se situam muitas vezes em uma realidade oposta à da maioria da população brasileira, principalmente no que se refere à sua composição racial.

Via de regra há pouca - ou nula - representatividade e protagonismo negro nos processos avaliativos. Do mesmo modo, a dimensão racial raramente é colocada como elemento central nas investigações realizadas. Frequentemente são feitas interpretações da realidade ignorando-se o fato de que no Brasil as desigualdades raciais e o racismo estruturam as relações sociais e, nesse sentido, exercem grande influência sobre a dinâmica e o resultado dos programas e políticas que são objeto dos próprios processos de avaliação.

É perceptível também o fato de que o racismo estrutural é, muitas vezes, uma categoria de análise secundarizada - quando não ignorada - nos processos avaliativos, muito embora constitua uma concepção que possibilita explicar as realidades do nosso território, um país majoritariamente negro no qual o racismo ainda se coloca como norma.

O Movimento Lente Preta surge e manifesta-se contrariamente a processos de avaliação que remontam exclusões e fogem a um olhar mais amplo da realidade ao desconsiderar que nesta sociedade o racismo ainda determina a forma como pensamos, escolhemos e agimos no mundo. Este movimento de avaliadoras/es negras/os se afirma no campo avaliativo enfatizando a importância de que projetos, programas e políticas sejam avaliados em busca de equidade, desvelando e buscando encontrar respostas para o enfrentamento ao racismo a partir de leitura de mundo que considere o nosso olhar e contribuições de modo que:

- As pessoas negras se tornem sujeitos ou atrizes/atores que manejam e demandam os processos de avaliação e, nesse sentido, não sejam apenas objeto de tais investigações;

- O enfrentamento ao racismo constitua uma medida ou parâmetro para analisar a efetividade de um projeto social ou política pública, e que as avaliações produzidas sejam indutoras de processos de inclusão e reparação;

- As produções de intelectuais negras/os sejam consideradas dentre os referenciais e abordagens adotados no percurso da avaliação e na formação de avaliadoras/es, permitindo que acessem e dialoguem com outras leituras de mundo, com conhecimentos científicos e escritos produzidos por esses/as intelectuais, evitando reproduzir epistemicídios;

- Os recortes estabelecidos nas avaliações considerem as diferentes identidades e as subjetividades dos sujeitos presentes no território brasileiro, evitando reducionismos e apagamentos;

- As narrativas produzidas por e sobre pessoas negras e territórios negros não remontem o olhar da carência e subserviência, mas que atentem e reconheçam o potencial político, cultura, social e de resistência destes grupos;

- A ideia de equidade contenha o enfrentamento ao racismo, contribuindo para que dívidas históricas sejam reparadas;

- As avaliações sejam alicerçadas em um Brasil real que é também negro e diverso;

- Que sejam criadas e utilizadas metodologias interseccionais, que, partindo das epistemologias fundadas pelo feminismo negro, considerem e evidenciem a existência de uma matriz colonial moderna baseada na opressão de raça, gênero, orientação sexual, 
classe social e de pessoas com deficiência. Sem esse olhar não podemos aprofundar, de fato, a análise dos aprendizados e resultados de uma avaliação.

O Lente Preta surge como um movimento de profissionais negras/os, estudiosas/os e especialistas em avaliação e monitoramento de projetos, com o propósito de afirmar e visibilizar uma leitura negra do mundo e demonstrar que ela importa, também, nos processos avaliativos para que eles façam sentido.

Nossa negritude nos une e nos fortalece para que possamos mostrar nossa leitura de mundo sob as lentes de quem não só vê a questão racial, mas também as vive. Queremos protagonizar e dar concretude a projetos e processos de trabalho que nos reconheçam, que desvelem as desigualdades históricas de nosso país e apontem caminhos para combatê-las.

\section{Fonte de financiamento}

Não há.

\section{Conflito de interesse}

Não há. 